\title{
Analysis of Women's Image in Iranian TV Commercials Based on Barthes Visual Semiotics
}

\author{
Nooshin Azin \\ Department of Language, College of Humanities,Islamshahr Islamic Azad University; azin@iiau.ac.ir
}

Hossein Heidari Tabrizi

Doi:10.5901/mjss.2015.v6n6s1p415

Department of language, Khorasgan Islamic Azad University

\begin{abstract}
Media affect the lives of people. By producing a particular kind of advertisement or message, media can control and influence people's opinions and attitudes. In almost all modern societies, one of the major television genres is advertising (Cook, 2005). It not only gives information about services and products, but also builds a secondary discourse about society and power relations. Advertising has an important role in the representation of gender in a society. Thus For this study, five TV commercials broadcasted in Iran by IRIB in 22th May- 21th June 2014 were selected. These advertisements were chosen since they have significance in gender roles. Then in order to study women's image in Iranian TV commercials, Barthian semiological analysis describing the image on both levels of significance- denotative and connotative level- was utilized. The results demonstrated that the TV advertisements selected in this paper represent gender stereotypes and traditional gender division of labor.
\end{abstract}

Keywords: Barthes visual semiotics, Gender role, TV commercials, Image of women.

\section{Introduction}

In a modern world, mass media have a critical role. Information is broadcasted rapidly and entertainment is given to wide audiences. They include books, radio, television, press, and the internet. While the internet is regarded as the most expanding mode of communication in the modern world, TV still has a considerable domination, because of its audio visual quality. This quality gives it a great power in transferring ideologies and leads to the viewer emotional involvement.

\subsection{Stereotypes}

By simplifying and classifying obtained data, human beings categorize their world knowledge. Thus their cognitive schemes are formed. These schemes shape our world view and have a considerable effect on our social cognition. The stereotypes can be considered as the most significant types of schemes which are demonstrating the attitudes of a certain social group. Stereotypes show inadequate, biased and at times untrue representation of reality due to various process of generalization and simplification that they apply. They are resistant to change and mostly based on customs and traditions. According to Elliot Aronson (1972), an American psychologist, "Stereotypes are used to attribute the identical features to each member of a certain group without taking the existing differences among the members into consideration".

The social archetypes lead to a division of gender roles. Through the ages, a typical family ideal was" patriarchal" model. In the past, women were judged as low-status labors, dependent, loving mothers and wives, responsible for nurturing children and doing house work, while men were regarded as wage-earners, job-focused, firm and autonomous.

\subsection{Gender in mass media}

As Fairclough (1992) pointed out, gender stereotypes are still used by many social organizations like mass media. They often represent beliefs which, directly or indirectly legitimize existing power relations.

Mass media gives people information and enjoyment, on the other hand according to McLuhan (1964) it influences people lives by shaping their ideologies, thoughts and opinions. By unnoticeably conveying the dominant hegemonic beliefs, it can control people's social life. An Italian thinker, Antonio Gramsci, proposed an idea of "cultural hegemony" as a moral and intellectual controlling, discriminated from armed forced. 
Many Studies showed that commercials are stereotyped by gender (Counrtney and Whipple, 1983; Signoreill, 1985). The National Institute of Mental Health highlights these gender roles on television as follow : "(1) in male-female interaction, men are usually more dominant; (2) men on television are rational, ambitious, smart, competitive, powerful, stable, violent and tolerant, while women are sensitive, romantic, attractive, happy, warm, sociable, peaceful, fair, submissive and timid; and (3) for men, the emphasis is on strength, performance and skill; for women, it is on attractiveness and desirability and finally marriage and family are not important to television's men" (National Institute of Mental Health as cited in Lauer and Lauer, 1994, p73).

According to Davis (1990), in most cases TV shows good-looking, slim, young, and eye-catching females. The common age range is above 50 or below 35. Middle-aged females are uncommon (Beal, 1994). Women are constantly engaged in positions where their appearances consider more important than their thought, and powerless and inept deeds are normal (Boyer, 1986). Most men on TV are presented capable and smart (Boyer, 1986). Women are generally portrayed as sex object, and men depicted clumsy while managing children's needs (Basow, 1992).

In almost all modern societies, one of the major television genres is advertising (Cook, 2005). It not only gives information about services and products, but also builds a secondary discourse about society and power relations. Many specialists have argued that the demonstration of gender stereotypes essentially reflects the cultural, social, economic and political beliefs of the community (Dines and Humez, 1994; Gauntlett, 2002). Van Dijk similarly (1993) claims that the patriarchal ideals and values are still reflected on TV programs in modern world. Thus, advertising has an important role in the depiction of gender in a society.

A considerable amount of literature has been published on representation of gender in media. Shartiely (2005) studied the specific images of men and women in TV commercials. It traces that gender stereotyping in advertising rooted from disapproving viewpoints that are presented in real life situations. Another study by Lee (2004) draws our attention to the nature of females stereotyping in Singapore's TV production. The findings showed that women were represented in more varied roles. Though, patriarchy is still predominant to some extent. In their review, Signoreilli et al. (1991) indicated that commercials on MTV are gender-stereotyped. Assuming social constructivism, Ottosson and Cheng (2012) analyzed two movies in their thesis. Their study specified that characters do still show inclination towards patriarchies and certain challenging characters are almost unsuccessful.

Due to cultural and religious situation in Iran and in its mass media, women's display in advertisements follows certain rules and limitations. In Iran several attempts have been made to analyze women's image in commercials.

Amini (2010) in her paper claims that in typical advertisements in the modern world, instead of stereotypical image, women are more presented as a "sex object". She added that in Iran, commercials utilized gender stereotypical images as well; the only difference is in the shape of "women's representation ".

In another study analyzing Islamic Republic of Iran (IRIB) commercials, Payande (2006) listed these stereotypes for women: (1) being housewife; (2) being mother; (3) naturalizing gender division of labor and ; (4) acting as good models for their little daughters. He believes that commercials not only transfer information about quality of products but also reflect social relations and cultural values of the society. Carter and Steiner (2004) support this view by considering media as "an important area of study which has the power to signify what is socially acceptable".

\subsection{Semiotics}

Language is a system of signs: written words, sounds, and images are varied types of signs. The origins of semiology are found with the work of the French linguist, Ferdinand De Saussure (1857-1913). He defined semiotics as 'the science of signs'. He classified the sign into two basic components: a sound component which he called signifier and a conceptual component which he named the signified. This signified or conceptual component is not just a material object, it can be the thought or the idea of an object. The association between the signified and the signifier is arbitrary; it is largely influenced by culture or context of use. In the case of the media studies, a signifier is any image which is conveyed to the audience. Though signifiers and signified can be separated by semiologists; they form a unit called a "sign".

Charles Pierce (1839-1914), the American philosopher, similarly studied semiology. He proposed theories to show how signs communicate ideas, attitudes and beliefs to us. Pierce stresses the dynamic relations between sign, interpretant, and object which result in semiosis or the process of signification. similar to De Saussure, Pierce model is structural, but Dissimilar to Pierce's triadic structure, Saussure's system of sign is dyadic (the signified and the signifier).

While their model of sign is mainly linguistic, the philosopher Roland Barthes consider image in his system of signs. Barthes believed that the use of signs in society is a way of normalizing the world corresponding to a bourgeoisie viewpoint. This normalization was entitled a 'myth'. According to Barthes "myth does not deny things, on the contrary, its function is to talk about them; simply, it purified them, it makes them innocent, it gives them a natural and eternal 
justification ........it is natural and goes without saying: I am reassured" (Barthes 1973:143).

In this manner, the signs that relayed from the media can communicate a variety of messages to its audience including social and cultural values. They can act as a means of domination; they can form the structure of public understanding and perception (Bouzida, 2014).

Semiology then helps the interpreter recognize how signs are employed and understood within the media. Since media uses various signs to convey predominant stereotypic values in any society, visual analysis of women in the media, especially in television commercials, can reflect significant social relations and cultural values of the society. Accordingly, in this paper it is tried to inspect Iranian TV commercials based on Barthes visual semiotics.

\section{Method}

\subsection{Research approach}

\subsubsection{Barthes semiological Approach}

One of the notable figures in the French school structuralism semiotics was Roland Barthes. In Barthian visual semiotics, the image has two layers:

1) Denotation or 'what, or who, is being depicted here?'

2) Connotation or' what ideas and values are expressed through what is represented, and through the way in which it is represented?' (Van Leeuwen, 2001)

Barthes believes, through complicated semiotic collaboration and interaction, the image is associated with ideological and social aspects which are interpretable at the connotative level.

In media studies, Barthes methodology is greatly practical and his semiological study can be used as an analytical tool for contemporary media studies. A new challenge for analyzing media is introduced to identify the connotative meaning. The semiological analysis helps us recognize how media produce values and meanings from system of signs. Using semiology as a qualitative method, researchers can realize the hidden meanings of the images, advertisements, movies, pictures... considering the socio-cultural setting.

Like so, in the present study in order to study the hidden meanings of women's image in Iranian TV commercials, Barthian semiological analysis describing the image on both levels of significance- denotative and connotative level- is utilized.

\subsection{Sampling}

The purposive sampling method, the most common sampling method in qualitative research, is used in this study (Creswell, 2007). The purposive sampling approach is employed when samples should have particular characteristics that will enable comprehensive investigation and understanding of the main questions that the researcher wants to explore (Ritchie \& Lewis, 2003).

For this study, five TV commercials broadcasted in Iran by IRIB in 22th May- 21th June 2014 (Khordad 1393) were selected. These advertisements were chosen since they have significations in gender roles. From these samples, one could understand how Iranian television represents women in advertising.

\section{Analysis of Advertisements Based on Barthian Level of Signification}

\subsection{Advertisement one: Sepid washing machine powder}

\subsubsection{Denotative level}

A little girl:"Mom, if you wash my clothes with Sepid (Sepid means white in Persian), will it remove the chocolate spots? The mother:"Let me ask my mom."

Then her mom called her grandmother:"Hi, mom! Does Sepid remove clothes stains?" "Yes, it does remove, but let me ask my mother again" her grandmother said.

Then her grandmother called her great grandmother: "Mom! Does Sepid protect the color of clothes?" Her great grandmother emphasizes: "Yes, it does, but let me look at my mother's diary", and her diary was shown with this sentence bolded: There is no powder Superior to Sepid powder. 

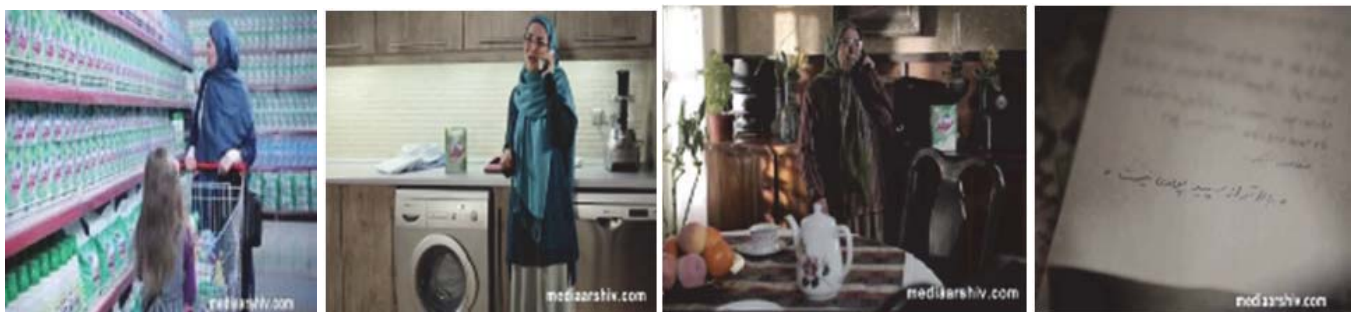

\subsubsection{Connotative level}

In this advertisement, for several generations women are portrayed to be responsible for washing the clothes of family members. The little girl internalizes and models this role. Based on the dominant social routine in Iran, girls should attend beside their mothers, follow their footsteps at home from early childhood and learn the methods of housekeeping. In this way, girls shape their identity. Washing is one of the main household tasks and nothing has changed from past to present. A device such as the washing machine and goods like washing machine powder associated with women. Presenting a mother as a housewife with her little daughter insist on the projection of traditional female role as a norm or stereotype.

\subsection{Advertisement two: 8-piece Agrin kitchen ware}

\subsubsection{Denotative level}

The second TV commercial advertises home appliances: 8-piece Agrin kitchen ware (Agrin is a Kurdish name means fiery). A young lady is sitting behind the table in the kitchen. She looks weary; she is tired of her worn-out saucepans. The voice of a man is heard while the woman is working. He says, "Forget cooking with old kitchen ware... don't worry about cookery with 8-piece Agrin kitchen ware... it has 3 pans, 2 frying pans in different sizes.... enjoy cooking with Agrin and now serve your guests easily with Agrin and let others admire you....the home becomes real home just with Agrin." Along with the man voice in background the woman is serving and dining her husband and son. After using Agrin kitchen ware she becomes happy and serves her guests happily. Consequently her husband and son look happier and more satisfied.
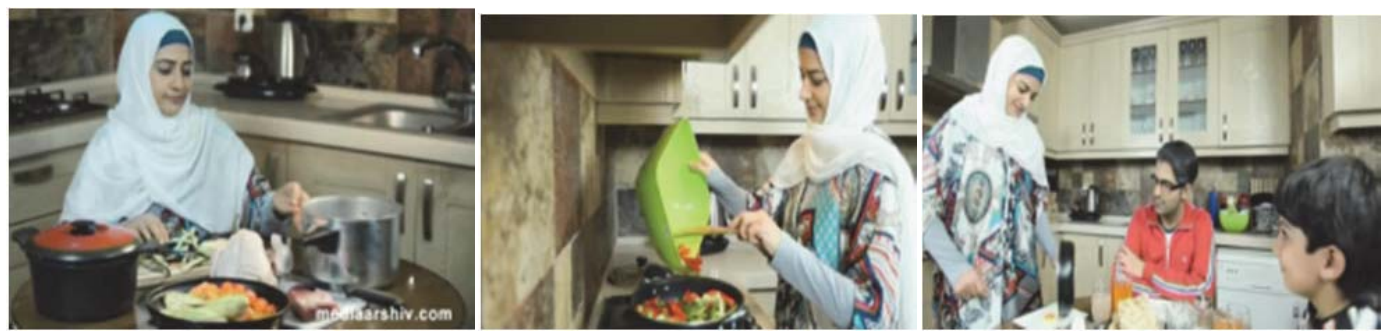

\subsubsection{Connotative level}

One of the assumptions is gender division of labor. The woman is alone in the kitchen. Having time worn kitchen ware makes her look sad and exhausted. Buying new brand pans solve her problems. The brand new set is all she needs. After getting this set, she serves her family and guests better. She looks happy now. Again in this advertisement, a woman is portrayed to be responsible for cooking and feeding her family members. Kitchen equipment such as the saucer pans have been considered as properties for women. Representation of man in this advertisement is in accordance with his traditional role who is sitting and waiting to be fed. Presenting the woman as a house wife, reflects the traditional or expected women job confined in the kitchen. 


\subsection{Advertisement three: Goli dishwashing liquid}

\subsubsection{Denotative level}

The third TV commercial presents"Goli dish washing liquid" (Goli means red). The advertisement starts with young lady's close up. She has lots of guests; she is serving and dining them. In one scene her husband helps her and brings food. She invites the guests to eat, but at the same time she imagines all dishes left for her to wash. Thus she becomes anxious and stressed. While we see these scenes, a woman's voice is heard. She says "Being together is valuable .... Do not waste it by worrying about the left dishes ...Goli with great cleaning and lathery power wash greasy dishes easily... enjoy more from enjoyable moments of your life.... Paxan (the name of the detergent company) is thinking about family wellbeing." At the same time we have a close up of the young lady, she is squeezing dish washing liquid on a dishcloth. Now she is smiling. In the final scene, we see all greasy dishes are washed. They are shining. At the background in a vague shot, after washing the dishes her husband brings her a glass of tea.
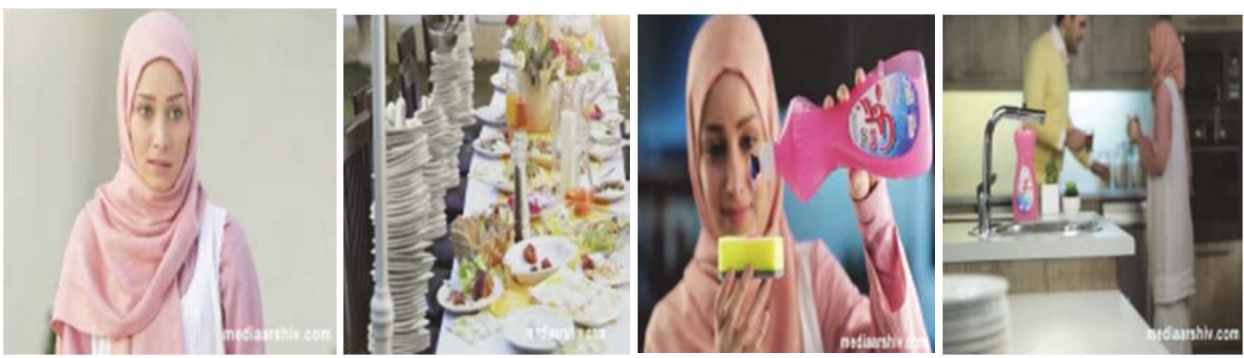

\subsubsection{Connotative level}

The main character is a young lady who is responsible for serving and dinning the guests and washing the party dishes. At this time, thick liquid with great lathery power shows up and helps her and all of a sudden, her worries turn to happiness and relief. Apparently, the advertisers try to neutralize the assumptions of patriarchal divisions of labor by showing two scenes that her husband helps her. In one shot he brings food, and in the last scene he offers his wife a cup of tea. Again we witness the projection of the gender division of labor. Serving guests and washing dishes are traditionally of feminine nature in Iranian society.

\subsection{Advertisement four: Tabiat Rice}

\subsubsection{Denotative level}

The fourth TV commercial promotes "Tabiat rice" (The word Tabiat means nature). A male -voiced promoting "Tabiat rice" is heard in the background. A woman arrives home with flower, rice, sweets....in her hands. She prepares food for the family with the Tabiat rice which she bought; she is concerned about her husband's reaction. Not only the wife but two other elderly women at the table who appear to be her mother and mother in law are concerned about the man reaction too. They looked each other and the man anxiously with doubt. When the man tastes the rice and nodes his head signifying his satisfaction, they breathe freely and look each other cheerfully.
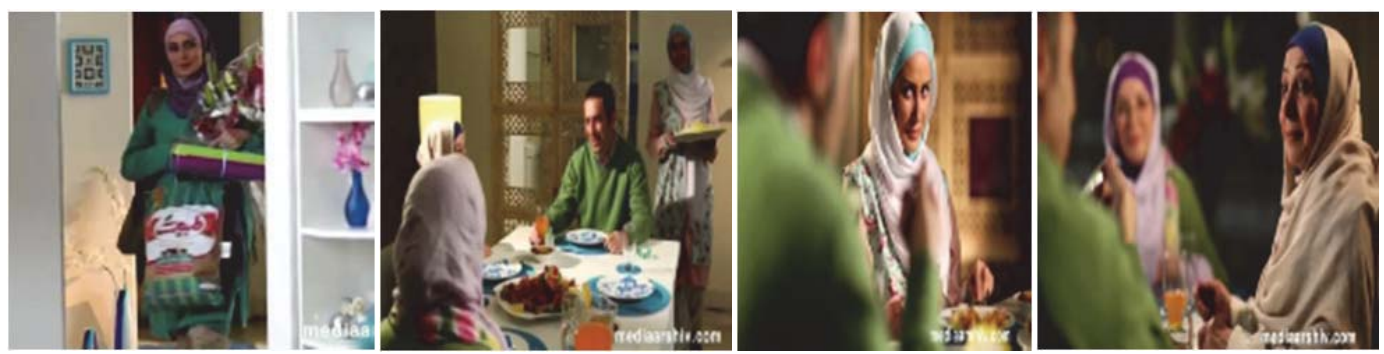


\subsubsection{Connotative level}

We see a woman arrives with a load of household shopping among them; there is a bag of rice. She has doubt about the quality of the rice and concerns about her husband's reaction. Not only this young lady but also her mother and mother in law who act as a model and sample of submissive traditional female, minds about the man's confirmation. In this advertisement, this is the woman who buys goods, who prepares food and concerns about husband's approval. Man sits at the table and acts as an approver.

Again, we are faced with gender division of labor. Such conditions help the stabilization of the superiority of male position and the low position of women; it is an attempt to represent the desirable woman who is inferior and submissive to her superior husband.

\subsection{Advertisement five: Persil detergent powder}

\subsubsection{Denotative level}

A large number of women are sitting on chairs and listening to a young lady who is standing on a platform and marketing Persil detergent (Persil is a proper name for this detergent). She says: "Welcome to Persil program where we solve washing problems". Then an elderly man in white arrives and explains about chemical features of Persil powder and how it removes stains. Then the marketing woman offered a box of powder to a woman and her little daughter and continues, "This powder is produced in Iran now ....and washing means....." All women rejoin: "Persil". A man voice is heard: "Washing means Persil".
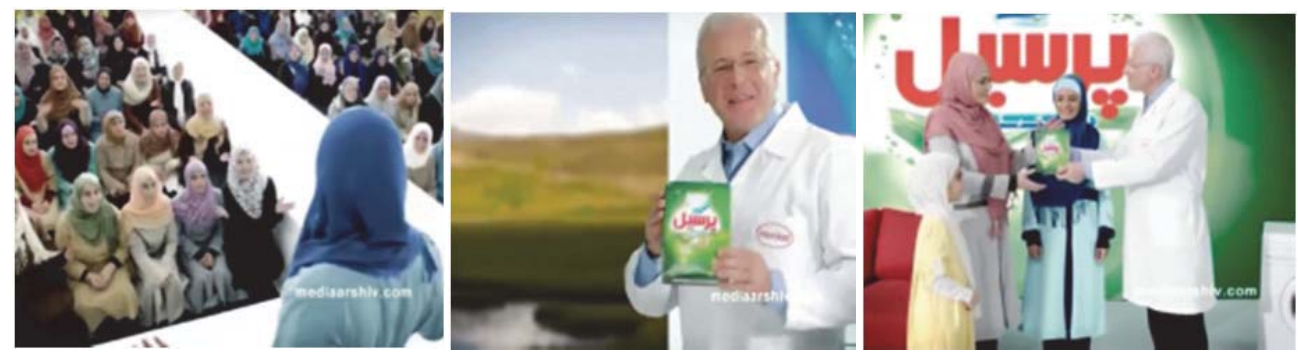

\subsubsection{Connotative level}

We have three cliché here: 1) a marketing person 2) consumers or users 3) a specialist. Marketing which is not so much prestigious job is done by a woman. The other group is consumers who are all women in different age ranges. Again just women are portrayed to be responsible for washing the clothes of family members. This responsibility is not in accordance with male identity. An elderly man in white is presented as a chemist. Among all these women, just one man presented as a person who has technical knowledge. It signifies the ideology of gender division of labor. The traditional views are reflected again in this commercial, contrary to all the advancement concerning woman's status in Iran.

In one scene, one box of detergent is gifted to a mother and her little daughter, to signify that the actions such as washing and cleaning in the context of Iranian society relate to women, and male identity refuses to accept this action. According to the dominant cultural discourse of society in Iran, girls should attend beside their mothers; follow their footsteps at home from early childhood. It implies that she should play her traditional future role.

This advertisement indicates that these tasks are part of the female nature and unchangeable. Thus, it leads to the stabilization and continuation of traditional female identity.

\section{Discussion}

Studies have frequently showed that commercials are stereotyped by gender (Counrtney \& whipple, 1983; Signoreilli 1985). Applying two layer Barthian visual analysis, this paper revealed how television commercials of kitchen appliances, detergents and food in Iran portray women. It indicates that television advertisements in Iran continue gender stereotyping. A division of gender roles can be identified based on the patriarchy family model and social prototypes. For 
the most part, women are portrayed simple and superficial. This confirms Van Evra (1990) assertion that numerous TV advertisers seem to depict an image of women as creatures who become extremely excited over a detergent's cleaning power, whose worlds are narrow and totally housebound, and who never discuss anything sophisticated or inspiring. Though doing housework, raising children, being a good and loving wife are worthwhile, but restricting women solely to these roles and eliminating them from important roles in a society are the main criticism here.

Mass media employs stereotypical personalities to control the audience conception of the world. The media create their own version of reality. These stereotypical characters influence children as well; in this way they internalize gender division of labor and develop their ideas about what is wrong and what is right. As Van Evra (1990) claims 'TV plays a significant role in child's growing belief.'

Moreover, stereotypes are largely utilized as one of the most common techniques of persuasion in the ads. In many parts of the world women are used as a sex object but in Iran because of religious circumstances women are not presented as "sex objects" in commercials, instead they are objectified to persuade people to buy some household cleaning products, cooking equipment, foodstuff... . The objectification exists in both cases; the only difference is in the form of representation.

In our time the diversities among female and male job in our society become smaller or even disappeared, however commercials still employ traditional gender stereotypes. Due to its responsibility for presenting the dominant social norms, TV is expected to act as "a mirror of the society". Generally, TV commercials in Iran do not represent what is really taking place in society. They overlook certain facts such as some women being busier in certain contexts. Today a family model tend to be more based on a partnership rather than on patriarchy.

As a final point, marketing specialists can act revolutionarily in their promoting and go beyond gender stereotyping. For having normal, well-balanced and high-spirited family, women should be open-minded, strong and free from social expectations. Stereotypical beliefs where women are inspired to be needy and polite, and men are urged to be determined and leader are not helpful. Outdated gender roles prevent impressive accomplishment. It is required for our children to nurture in an impartial gender atmosphere which inspires them to think they are effective in directing their societies, regardless of their gender.

\section{References}

Amini, A. (2010). Representation of women in commercials in Iran and the world. Book of the month: Social science, 26, 91-103.

Aroson, E. (1972). The social animal.W.H. Freeman.

Barthes, R. (1973). Mythologies.London:Paladin.

Basow, S.A. (1992). Gender stereotypes and roles,3rd ed.Pacific Grove, CA: Brooks/Cole Publishing Company.

Beal,C. (1994). Boys and girls: The development of gender roles. New York: McGraw-Hill, Inc.

Bouzida,F.(2014). The semiology analysis in media studies-Roland Barthes approach-Proceedings of SOCIOINT14-International conference on social sciences and humanities.

Boyer,P.J. (1986). TV turns to the hard boiled male. New York Times, February 16, p.H1 and H29.

Carter, C., \& Steiner, L. (2004). Critical readings: Media and gender. Maidenhead: Open University Press.

Cook, G. (2005). Discourse of advertising. New York: Taylor \& Francis.

Cresswell, J. W. (2007). Qualitative inquiry and research design: Choosing among the five traditions (2nd ed.). Newbury Park: Sage Publications.

Courtney, A.E., \& Whipple, T.W. (1983). Sex stereotyping in advertising, Lexington, MA: Lexington Books.

Davis, D.M. (1990). Portrayals of women in prime time network television: some demographic characteristics. Sex Roles, 23,325-332.

Dines,G. \& Humez, J.M. (1994). Gender, race and class in media. Newbury Park: Sage Publications.

Fairclough,N. L.(1992). Discourse and social change. Cambridge: Polity Press.

Gauntlett, D. (2002). Media, gender and identity. London: Routledge.

Hall, S. (ed.) (1997). Representation: Cultural representations and signifying practices. London: SAGE, Open University Press.

Lauer, R.H. \& Lauer, J.C. (1994). Marriage and family: The quest for intimacy. Madison, WI: Brown \& Benchmark.

Lee,Ch.W. (2004). Gender role stereotyping in television commercials. Advertising \& Society Review. Vo.5, 3, 2004

Lindzey, G., \& Aronson, E. (1968 \& 1985). The handbook of social psychology (2nd \& 3rd eds.). New York: Random House.

McLuhan,M .(1964). The medium is the message in: Understanding media. New York: Signet.

Ottosson, Th. \& Cheng, X. (2012). The representation of gender roles in the media.Bachelor's thesis in political science, University West. Payandeh, H. (2006). A critical review of TV commercials. Tehran: Rooz Negar publication.

Pierce, C.S. (1955). Philosophical writings of Pierce. Editor by J. Bachler. New York. Philosophical Library.

Ritchie, J. \& Lewis, J. (2003). Qualitative research practice: A guide for social science students and researchers. Thousand Oaks, CA: Sage.

Saussure, F. de (1974). Course in general linguistics. New York: Philosophical Library.

Seidman, S.A. (1999). Revisiting sex role stereotyping in MTV videos. International Journal of Instructional Media, 26, 11-22. 
Shartiely, E.N. (2005). The portrayal of the Tanzanian woman in TV commercials: is she a piece of soap, a house, or gold?.Africa \& Asia, 5,108-141.

Signoreilli, N. (1985). Role portrayed and stereotyping on television: An annotated bibliography of studies relating to women, minorities, aging, sexual behavior, health, and handicaps. Westport, CT: Greenwood.

Van Dijk, T.A. (1993). Stories and racism. In D.K. Mumby (ed.), Narrative and social control: Critical perspectives (pp. 121-42). Newbury Park, CA: Sage Publications.

Van Dijk, T.A. (2003). Critical discourse analysis. In D. Schiffrin, D. Tannet \& H. E. Hamilton (Eds.), The handbook of discourse analysis (pp. 353-371). MA: Blackwell publishing.

Van Evra, J. (1990). Television and child development. Hillsdale: Lawrence Erlbaum Associates.

Van Leeuwen, T. \& Jewitt, C. (Ed.) (2001). Handbook of visual analysis . London: Sage publication.

http://krytyka.org/gender-stereotypes-in-mass.media-case-study-analysis-

http://lucian.uchicago.edu/blogs/mediatheory/keywords/semiotics/

http://www.history.ac.uk/1807commemorated/media/methods/semiotics.html 